\title{
GAS ABSORPTION ACCOMPANIED BY AN IRREVERSIBLE SECOND-ORDER REACTION IN AN AGITATED VESSEL WITH A FLAT GAS-LIQUID INTERFACE
}

\author{
HaRUO HIKITA AND HARUO ISHIKAWA \\ Department of Chemical Engineering, University of Osaka Prefecture, Sakai 591
}

In previous studies ${ }^{7,8)}$, the rates of absorption of $\mathrm{H}_{2} \mathrm{~S}$ into aqueous $\mathrm{NaOH}$ solutions and of $\mathrm{CO}_{2}$ into aqueous $\mathrm{Na}_{2} \mathrm{CO}_{3}-\mathrm{NaHCO}_{3}$ solutions were measured in a baffled agitated vessel with a flat gas-liquid interface, these absorption processes taking place in the instantaneous reaction regime and the pseudo firstorder reaction regime, respectively. The experimental results obtained were in good agreement with predictions from the chemical absorption theory based on the Lévêque model. In the present work, experiments were carried out using the same agitated vessel for the absorption of $\mathrm{CO}_{2}$ into aqueous $\mathrm{NH}_{3}$ solutions, which may be considered to take place in the intermediate regime between the instantaneous and pseudo firstorder reaction regimes.

\section{Chemical Absorption Mechanism}

When $\mathrm{CO}_{2}$ is absorbed in aqueous $\mathrm{NH}_{3}$ solutions, the following reactions may take place in the liquid phase:

$$
\begin{aligned}
\mathrm{CO}_{2}+\mathrm{NH}_{3} & \rightleftharpoons \mathrm{H}^{+}+\mathrm{NH}_{2} \mathrm{COO}^{-} \\
\mathrm{H}^{+}+\mathrm{NH}_{3} & \rightleftharpoons \mathrm{NH}_{4}^{+} \\
\mathrm{CO}_{2}+\mathrm{OH}^{-} & \rightleftharpoons \mathrm{HCO}_{3}^{-} \\
\mathrm{HCO}_{3}^{-} & \rightleftharpoons \mathrm{H}^{+}+\mathrm{CO}_{3}^{2-} \\
\mathrm{CO}_{2}+\mathrm{H}_{2} \mathrm{O} & \rightleftharpoons \mathrm{H}^{+}+\mathrm{HCO}_{3}^{-} \\
\mathrm{H}^{+}+\mathrm{OH}^{-} & \rightleftharpoons \mathrm{H}_{2} \mathrm{O}
\end{aligned}
$$

Under circumstances of practical importance, the following condition is satisfied:

$$
\begin{gathered}
k_{\mathrm{H}_{2} \mathrm{O}}+k_{\mathrm{OH}}\left[\mathrm{OH}^{-}\right]_{i} \\
k_{2}\left[\mathrm{NH}_{3}\right]_{i}
\end{gathered}
$$

This means that reactions (c) and (e) are very much slower than reaction (a), and can be ignored in the thin diffusion zone near the gas-liquid interface. Thus, in this zone, the primary overall reaction between $\mathrm{CO}_{2}$ and $\mathrm{NH}_{3}$ is the sum of reactions (a) and $(\mathrm{b})^{2,4)}$ :

$$
\mathrm{CO}_{2}+2 \mathrm{NH}_{3} \rightleftharpoons \mathrm{NH}_{4}{ }^{+}+\mathrm{NH}_{2} \mathrm{COO}^{-}
$$

Reaction (a) is the rate-controlling step of reaction

Received June 2, 1977. Correspondence concerning this article should be addressed to H. Hikita. $(\mathrm{g})$, because reaction (b) is a proton transfer reaction and can be regarded as instantaneous. Further, reaction (g) has an equilibrium constant of the order of $10^{4} / / \mathrm{g}-\mathrm{mol}^{2}$ and thus can be treated as an irreversible second-order reaction with a stoichiometric coefficient of 2 . In the liquid bulk, however, the removal of free $\mathrm{CO}_{2}$ by reactions (c) and (e) causes reaction (a) to take place in the reverse direction, leading to the release of part of the free $\mathrm{NH}_{3}$ according to the following overall reaction:

$$
\mathrm{NH}_{2} \mathrm{COO}^{-}+\mathrm{H}_{2} \mathrm{O} \rightleftharpoons \mathrm{NH}_{3}+\mathrm{HCO}_{3}^{-}
$$

The rate of reaction (h) is controlled by the rates of reactions (c) and (e), since the reverse reaction of (a) is rapid. If both reactions (c) and (e) are rapid compared to the diffusion of the free $\mathrm{CO}_{2}$, i.e. when the condition $^{1)}$

$$
k_{\mathrm{H}_{2} \mathrm{O}}+k_{k_{\mathrm{L}}^{*}-}\left[\mathrm{OH}^{-}\right]_{0} \gg 1
$$

is fulfilled, all the reactions are at equilibrium in the bulk of the liquid, this situation being termed the "final equilibrium"2). Under the experimental conditions covered in the present work, the final equilibrium may be considered to be established in the bulk of the liquid, because the mass transfer coefficient and the interfacial area per unit volume of liquid are not so large.

For absorption with an irreversible second-order reaction represented by $\mathrm{A}+2 \mathrm{~B} \rightarrow$ products, the Lévêque model solution for the reaction factor can be closely approximated by the following equations ${ }^{3)}$ :

$$
\begin{array}{ll}
\beta=\gamma \eta+0.474715 /(\gamma \eta)^{2} & (\gamma \eta \geq 2.4) \\
\beta=1+\sum_{j=1}^{\infty} b_{j}(\gamma \eta)^{2 j} & (\gamma \eta \leq 2.4)
\end{array}
$$

Here $b_{1}, b_{2}, \ldots, b_{j}$ are numerical constants and are given in tables in references ${ }^{3,7}$, and $\gamma$ and $\eta$ are dimensionless parameters defined by:

$$
\begin{aligned}
& \gamma=\sqrt{k_{2} B_{0} D_{A} / k_{L}^{*}} \\
& \eta=\sqrt{ }\left(\beta_{\infty}-\beta\right) /\left(\beta_{\infty}-1\right)
\end{aligned}
$$

where $\beta_{\infty}$ is the reaction factor for absorption with an instantaneous reaction and can be obtained from ${ }^{3}$ ? 


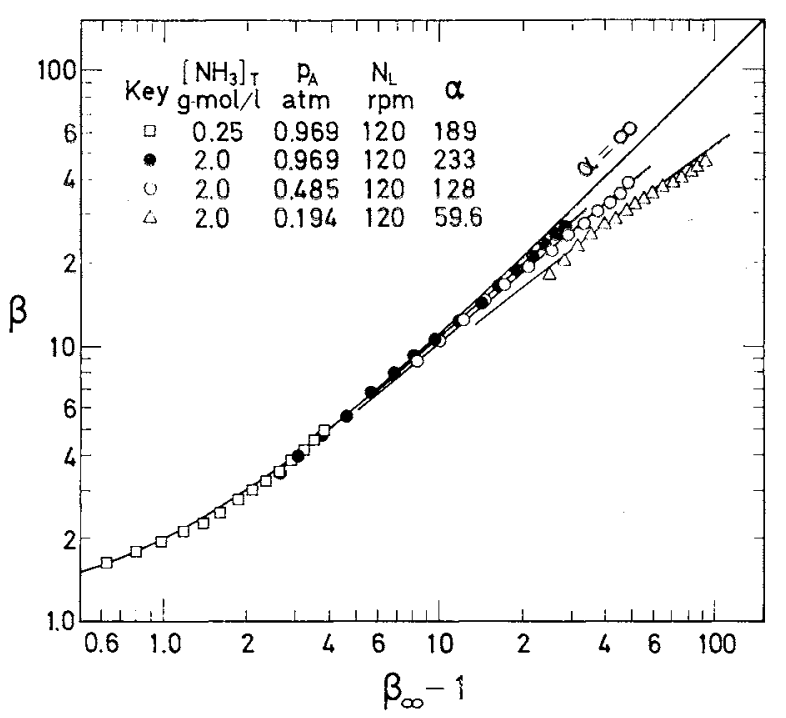

Fig. 1 Reaction factor for absorption of $\mathrm{CO}_{2}$ into aqueous $\mathrm{NH}_{3}$ solutions at $25^{\circ} \mathrm{C}$

$$
\begin{aligned}
\beta_{\infty}= & \Gamma(1 / 3, \infty) / \Gamma(1 / 3, \sigma) \\
\left(\frac{D_{B}}{D_{A}}\right)^{2 / 3}\left(\frac{B_{0}}{2 A_{i}}\right)= & \frac{\Gamma(1 / 3, \infty)-\Gamma\left(1 / 3, \sigma D_{A} / D_{B}\right)}{\Gamma(1 / 3, \sigma)} \\
& \times \exp \left[\sigma\left(\frac{D_{A}}{D_{B}}-1\right)\right]
\end{aligned}
$$

For the analysis of experimental data obtained in a semi-batch gas-liquid contactor such as an agitated vessel, the plot of $\beta$ vs. $\left(\beta_{\infty}-1\right)$ with a new dimensionless quantity $\alpha$ which is independent of $B_{0}$ as parameter is very useful, as indicated by Hikita and Ishi$\mathrm{kawa}^{6}$. According to the Lévêque model, $\alpha$ for $\mathrm{ab}$ sorption with an irreversible second-order reaction of the form $\mathrm{A}+2 \mathrm{~B} \rightarrow$ products is given by ${ }^{6\rangle}$

$$
\begin{aligned}
\alpha & =2 k_{2} D_{A}\left(D_{A} / D_{B}\right)^{2 / 3} A_{i} / k_{L}^{* 2} \\
& =\gamma^{2} /\left\{\left(D_{B} / D_{A}\right)^{2 / 3}\left(B_{0} / 2 A_{i}\right)\right\}
\end{aligned}
$$

Thus, in the present work, the experimental data of $\beta$ calculated from the measured absorption rates were plotted against $\left(\beta_{\infty}-1\right)$ and were compared with the theoretical lines calculated from Eqs. (3) and (5) to (8).

\section{Apparatus and Procedure}

The agitated vessel was of $12.3 \mathrm{~cm} \mathrm{I.D.} \mathrm{and} \mathrm{was} \mathrm{the}$ same as that used in the previous work ${ }^{7}$. The experimental procedure is also similar to that employed in the previous work ${ }^{7}$. The vessel was operated batchwise with respect to the liquid. All the experiments were carried out at $25^{\circ} \mathrm{C}$.

The gas phase was pure $\mathrm{CO}_{2}$ or a mixture of $\mathrm{CO}_{2}$ and air saturated with water vapor. The partial pressure of $\mathrm{CO}_{2}$ in the gas phase was varied from 0.19 to $0.97 \mathrm{~atm}$. The absorbing liquids used were aqueous $\mathrm{NH}_{3}$ solutions of concentrations from 0.25 to $2.0 \mathrm{~g}$ $\mathrm{mol} / \mathrm{l}$. The gas stirrer was driven at a constant speed of $500 \mathrm{rpm}$ in dilute $\mathrm{CO}_{2}$ runs. However, the gas phase in the vessel was not agitated in pure $\mathrm{CO}_{2}$ runs.
The stirring speeds of the liquid stirrer were 120 and $240 \mathrm{rpm}$.

The rate of absorption of $\mathrm{CO}_{2}$ was obtained from the graphical differentiation of the curve of the amount of $\mathrm{CO}_{2}$ absorbed vs. time. The amount of $\mathrm{CO}_{2} \mathrm{ab}-$ sorbed into the solution was determined as a function of time by measuring the decrease in volume of pure $\mathrm{CO}_{2}$ enclosed in a soap-film meter.

The free $\mathrm{NH}_{3}$ concentration in the bulk of the solution was calculated on the assumption that the bulk of the liquid had attained final equilibrium composition by using the method of van Krevelen et $a l^{10}{ }^{10}$.

\section{Results and Discussion}

Some typical experimental results are presented in Fig. 1 as a $\log -\log$ plot of $\beta$ against $\left(\beta_{\infty}-1\right)$, as suggested by Hikita and Ishikawa ${ }^{6)}$. The reaction factor $\beta$ in the ordinate was calculated from the measured value of absorption rate using the values of $A_{i}$ and $D_{A}$ estimated by the methods described by Hikita $e t$ al. ${ }^{4}$ ) and the value of $k_{L}^{*}$ predicted from the empirical equation given by Hikita and Ishikawa ${ }^{5\rangle}$. The value of $\beta_{\infty}$ in the abscissa was calculated from the theoretical equations (6) and (7) using the value of $\left(D_{B} / D_{A}\right)$ obtained by the method proposed by Hikita et al. ${ }^{4}$.

The solid lines in Fig. 1 are the theoretical lines based on the Lévêque model for absorption with an irreversible second-order reaction, and were calculated from Eqs. (3) and (5) to (8), taking the numerical values shown on the graph as $\alpha$. These values of $\alpha$ are the arithmetic means of the values calculated at beginning and end of the runs. The values of $A_{i}, D_{A}$, $\left(D_{B} / D_{A}\right)$ and $k_{L}^{*}$ were predicted by the methods described above, and the value of $k_{2}$ was estimated from the empirical equation of Pinsent et al. ${ }^{9}$. The uppermost line for $\alpha=\infty$ represents the theoretical equation for absorption with an irreversible instantaneous reaction, i.e. $\beta=\beta_{\infty}$. As can be seen in this figure, the experimental data points are in good agreement with

\begin{tabular}{|c|c|c|}
\hline$A_{i}$ & $\begin{array}{l}=\text { interfacial concentration of } \mathrm{CO}_{2} \text { in } \\
\text { solution }\end{array}$ & {$[\mathrm{g}-\mathrm{mol} / / \mathrm{l}$} \\
\hline$a$ & $\begin{array}{l}=\text { interfacial area per unit volume } \\
\text { of solution }\end{array}$ & {$\left[\mathrm{cm}^{2} / \mathrm{cm}^{3}\right]$} \\
\hline$B_{0}$ & $\begin{aligned} &= \text { concentration of } \mathrm{NH}_{3} \text { in bulk of } \\
& \text { solution }\end{aligned}$ & {$[\mathrm{g}-\mathrm{mol} / \mathrm{l}]$} \\
\hline$b_{j}$ & $=$ coefficient in Eq. $(3 \mathrm{~b})$ & {$[-]$} \\
\hline$D_{A}, D_{B}$ & $\begin{array}{l}=\text { liquid-phase diffusivities of } \mathrm{CO}_{2} \\
\text { and } \mathrm{NH}_{3} \text { in solution }\end{array}$ & {$\left[\mathrm{cm}^{2} / \mathrm{sec}\right]$} \\
\hline$k_{2}$ & $\begin{aligned}= & \text { second-order forward rate constant } \\
& \text { for reaction (a) }\end{aligned}$ & {$[l / \mathrm{g}-\mathrm{mol} \cdot \mathrm{sec}]$} \\
\hline$k_{\mathrm{H}_{2} \mathrm{O}}$ & $\begin{aligned}= & \text { pseudo first-order forward rate } \\
& \text { constant for reaction (e) }\end{aligned}$ & {$[1 / \mathrm{sec}]$} \\
\hline
\end{tabular}
the theoretical lines. Further, the other experimental data, omitted from Fig. 1 for clarity, also agree well with the theoretical predictions.

\section{Nomenclature}




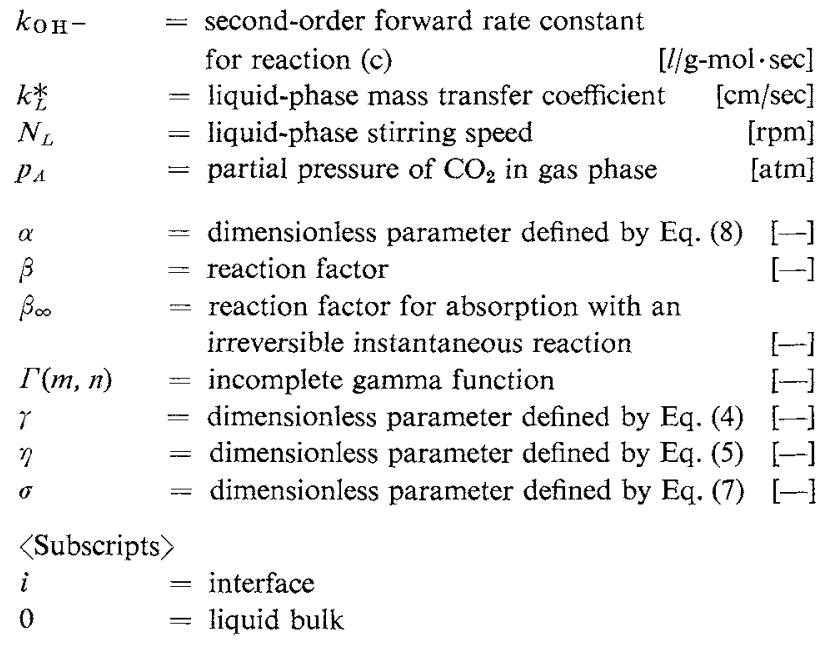

Literature Cited

1) Danckwerts, P. V.: "Gas-Liquid Reactions", p. 171,
McGraw-Hill, New York (1970).

2) Danckwerts, P. V. and K. M. McNeil: Trans. Inst. Chem. Engrs. (London), 45, T32 (1967).

3) Hikita, H., S. Asai and H. Ishikawa: Bull. Univ. Osaka Pref., A22, 57 (1973).

4) Hikita, H., S. Asai and Y. Himukashi: Kagaku Kögaku, 35, 1021 (1971).

5) Hikita, H. and H. Ishikawa: Bull. Univ. Osaka Pref., A18, 427 (1969).

6) Hikita, H. and H. Ishikawa: Kagaku Kögaku, 37, 1054 (1973).

7) Hikita, H. and H. Ishikawa: Kagaku Kogaku Ronbunshu, 1, 45 (1975).

8) Hikita, H., H. Ishikawa and Y. Murakami: Bull. Univ. Osaka Pref., A19, 349 (1970).

9) Pinsent, B. R. W., L. Pearson and F. J. W. Roughton: Trans. Faraday Soc., 52, 1594 (1956).

10) van Krevelen, D. W., P. J. Hoftijzer and F. J. Huntjens: Rec. Trav. Chim., 68, 191 (1949).

\title{
INTERFACIAL TURBULENCE DURING ABSORPTION WITH REACTION
}

\author{
Eizo SADA, Hidehiro KUMAZAWA, M. A. BUTT and J. E. LOZANO \\ Department of Chemical Engineering, Nagoya University, Nagoya 464
}

Interfacial turbulence induced by surface tension gradients (the Marangoni instability) can appear as a result of chemical absorption. In particular, instability may be easily established in the entrance region of any absorption equipment because the liquid surface is not almost contaminated shortly after the surface is formed. Therefore, in laboratory absorbers such as a laminar liquid-jet apparatus or a wetted wall column, far higher absorption rates are apt to be encountered than predicted by the penetration theo$r y^{1,3,4)}$. In previous papers ${ }^{3,4)}$, we measured the variation of interfacial turbulence accompanying carbon dioxide absorption into amine solutions with gas-liquid exposure time and amine concentration by the tracer gas desorption technique. The variation with concentration of the liquid-phase reactant was found to be very similar to the dynamic surface tension during chemical absorption. It is the purpose of this paper to investigate the interfacial turbulence induced by the Marangoni effect during chemical absorption in a wider range of gas-liquid contact times for the system of carbon dioxide-monoisopropanolamine. To this end, (1) absorption of carbon dioxide in

Received June 0, 1977. Correspondence concerning this article should be addressed to E. Sada, Dept. of Chem. Eng., Kyoto Univ., Kyoto 606. aqueous solutions of monoisopropanolamine (MIPA) with and without surface-active agent was performed using a laminar liquid-jet and (2) the desorption rates of inert tracer gas (ethylene) from the liquid-phase reactant with and without surface-active agent were measured under reacting and non-reacting conditions in the laminar liquid-jet and the wetted wall column.

\section{Experimental}

\subsection{Absorption of carbon dioxide into aqeuous solu-} tions of MIPA

The chemical absorption rates of carbon dioxide into aqueous solutions of MIPA were measured in a laminar liquid-jet. The laminar liquid-jet apparatus was the same as in our previous work ${ }^{4,5,6}$. For each experimental run, gas-liquid contact times were varied by changing the jet length but keeping the liquid flow rate constant. The gas-liquid contact time ranged from 0.002 to $0.02 \mathrm{sec}$. Experiments were performed with and without adding surface-active agent to the absorbent. The surface-active agent was a pure reagent grade of poly ( 10 moles) oxyethylene nonyl phenol ether. The amount of surface-active agent to absorbent was $0.025 \mathrm{vol} \%$. The gas phase was pure carbon dioxide saturated with water vapor. 